\title{
Analysis of Human Spleen Contamination
}

\section{Martin Kopani ${ }^{1}$, Martin Weis ${ }^{2}$, Jan Jakubovsky}

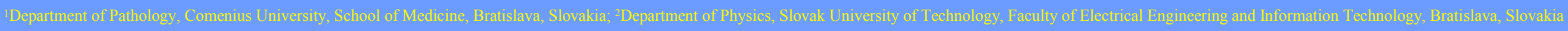
Introduction

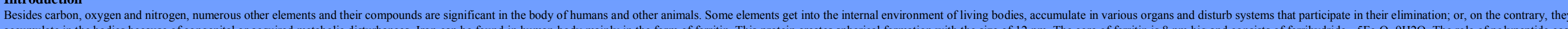

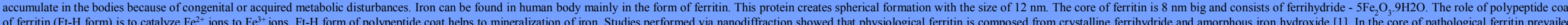

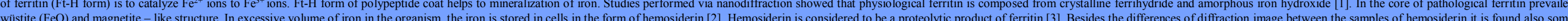

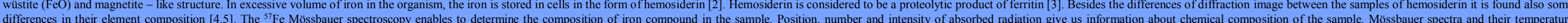
dependence are characteristic for each iron compound. Biomimetic approach to material synthesis exhibits novel properties. Magnetic materials attract considerable interest both from biological point of view as well as their technological application [6].

\section{Results and Discussion}

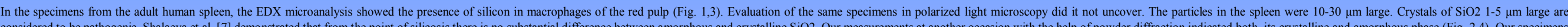

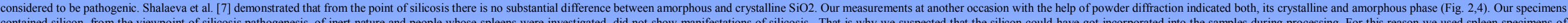

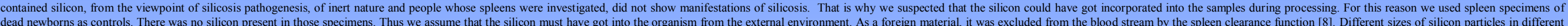
dead newborns as controls. There was no silicon present in those specimens. Thus we assume that the
parts of the organism were described in electron microscopy with EDAX analysis by Kodaka et al.[9].

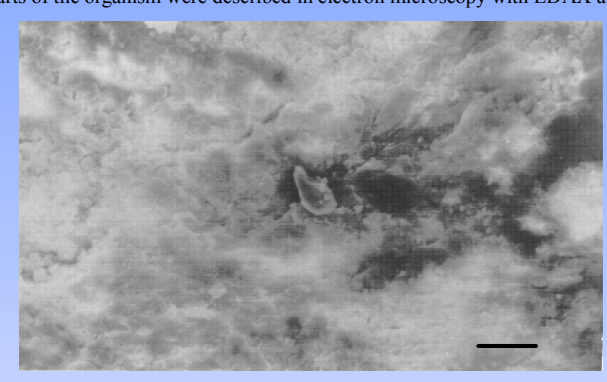

Fig. 1 The particle contains sulphur, aluminum, silicon, chlor
potassium, calcium and copper. SEM micrograph, line size is $10 \mu \mathrm{m}$.

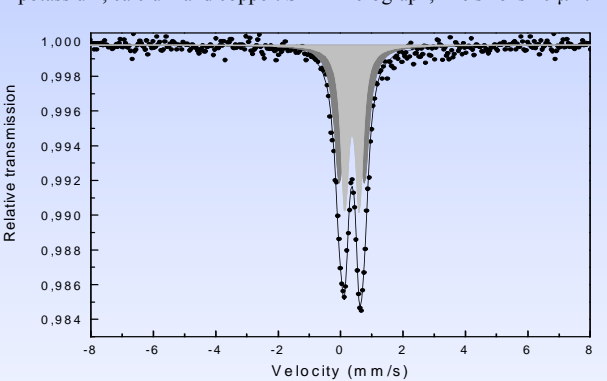

\begin{tabular}{|c|c|c|c|}
\hline Component & $\begin{array}{c}\text { Isomer shift } \\
{[\mathrm{mm} / \mathrm{s}]}\end{array}$ & $\begin{array}{c}\text { Quadrupole } \\
\text { splitting [mm/s] }\end{array}$ & $\begin{array}{c}\text { Fraction } \\
{[\%]}\end{array}$ \\
\hline 1 & 0.36 & 0.8 & 50 \\
\hline 2 & 0.37 & 0.46 & 50 \\
\hline
\end{tabular}

Tab. 1 Results of isomer shift and quadrupole splitting of spleen tissue after splenectomy with no signs of spleen disease. EDX analysis reveals spectral splenectomy with no signs of spleen dis
lines of $\mathrm{Mg}, \mathrm{Al}, \mathrm{Si}, \mathrm{P}, \mathrm{S}, \mathrm{Ca}, \mathrm{K}, \mathrm{Zn}$ and $\mathrm{Fe}$

\section{Discussion}

The investigation of Perls' Prussian Blue stained slides by light microscope indicates iron depositions in samples with diagnosis of hemochromatosis and hereditary spherocytosis. EDX microanalysis reveals multielemental composition. The core in normal tissue is ferrihydrite - $5 \mathrm{Fe}_{2} \mathrm{O}_{3} \cdot 9 \mathrm{H} 2 \mathrm{O}$ with various amount of phosphorus. Sample of spleen tissue with no signs of spleen disease can contain ferrihydrite (Tab. 1, component 1). Presence of vestigial amounts of some elements significantly influences oxidative-reduction status of iron, its structure, chemical composition and stoichiometry $[10,11]$. Phosphates influence extensively the morphology of iron oxides, if their precursor is ferrihydrite. The amount of phosphorus in iron oxides influences iron oxidation [12]. The interaction of iron $\mathrm{Fe}$ (II) with ferrihydrite leads to precipitation of goethite, lepidocrocite and magnetite [13, 14]. The magnetite and goethite-like form of hemosiderin that has been observed in some pathological tissues [15] was not detected (Tab. 2,3). The significant source of $\mathrm{Fe}(\mathrm{II})$ is the perturbation in erythrophagocytosis, which plays role in several diseases, including hemochromatosis [16]. We suppose that $\mathrm{pH}$ and time are significant factors influence biomineralization of iron in the human spleen
Fig. 2 XRD pattern taken from spleen contains aluminium, silicon, sulphur,

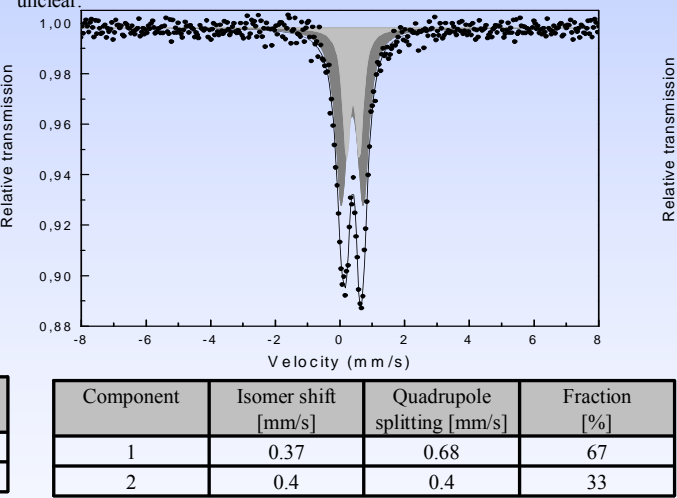

Tab. 2 Results of isomer shift and quadrupole splitting of spleen tissue from Tab. 2 Results of isomer shift and quadrupole splitting of spleen tissue from
hemochromatosis patient. EDX analysis reveals spectral lines of Mg, Al, P,
Si, S, Ca, K, Zn and Fe.

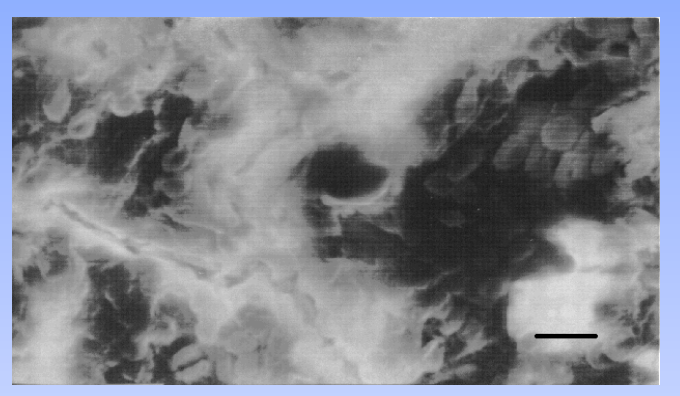

Fig. 3 The particles contain silicon, sulphur, chlorim
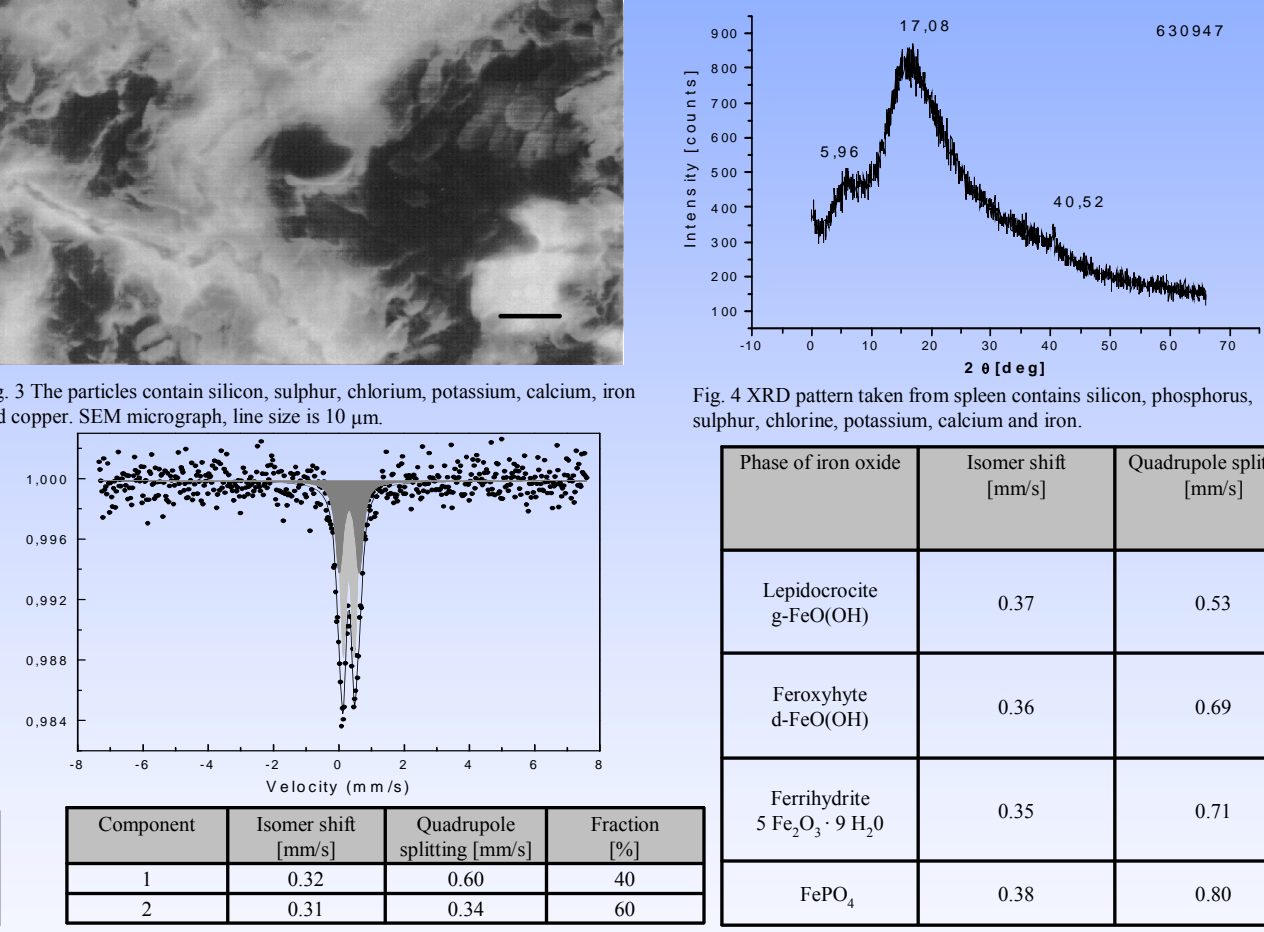

Fig. 4 XRD pattern taken from spleen contains silicon, phosphorus, sulphur, chlorine, potassium, calcium and iron.

\begin{tabular}{|c|c|c|}
\hline Phase of iron oxide & $\begin{array}{c}\text { Isomer shift } \\
{[\mathrm{mm} / \mathrm{s}]}\end{array}$ & $\begin{array}{c}\text { Quadrupole splitting } \\
{[\mathrm{mm} / \mathrm{s}]}\end{array}$ \\
\hline $\begin{array}{c}\text { Lepidocrocite } \\
\text { g-FeO(OH) }\end{array}$ & 0.37 & 0.53 \\
\hline $\begin{array}{c}\text { Feroxyhyte } \\
\mathrm{d}-\mathrm{FeO}(\mathrm{OH})\end{array}$ & 0.36 & 0.69 \\
\hline $\begin{array}{c}\mathrm{Ferrihydrite} \\
5 \mathrm{Fe}_{2} \mathrm{O}_{3} \cdot 9 \mathrm{H}_{2} 0\end{array}$ & 0.35 & 0.71 \\
\hline $\mathrm{FePO}_{4}$ & 0.38 & 0.80 \\
\hline
\end{tabular}

Tab. 3 Results of isomer shift and quadrupole splitting of spleen tissue with diagnosis of hereditary spherocytosis. EDX analysis reveals spectral lines of

List of possible phases of the iron oxides present in the studied tissues.

Literature

1. J.M. Cowley, D.E. Janney, R.C. Gerkin, P.R. Buseck, J. Struct. Biol. 131, 210-216, (2000)2. C. Seldon, M. Owen, J.M. Hopkins, T.J. Peters,

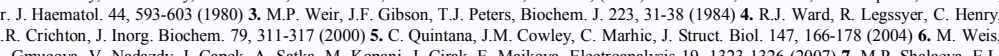
Gmucova, V. Nadazdy, I. Capek, A. Satka, M. Kopani, J. Cirak, E. Majkova, Electroanalysis 19, 1323-1326 (2007) 7. M.P. Shalaeva, E.L. Mordberg, A.V. Malashenko, R.V. Babakhanian, V.P. Feklistova, Gig. Tr. Prof. Zabol. 4, $11-17$ (1989) 8. M. Brozman, J. Jakubovsky, Z.
Mikrosk. Anat. Forsch. 1033 , 3316 (1989) 9. T. Kodaka, K. Debari, T. Sano, M. Yamada, Scann Micros. 8. 241 (1994) 10. T. Borch, Y. Masue, R.K. Kukkadapu, S. Fendorf, Environ. Sci. Technol. 41, $166-172$ (2007) 11. M. W. Jeen, J.L. Jambor, D. W. Blowes, R. W. G. Gillham, Environ. Sci.

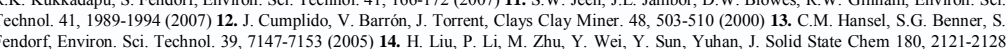
Fendorf, Environ. Sci. Technol. 39, 7147-7153 (2005) 14. H. Liu, P. Li, M. Zhu, Y. Wei, Y. Sun, Yuhan, J. Solid State Chem 180, 2121-2128
(2007) 15. D. Meryick, J. Webb, C. Cole, Inorg. Chim. Acta 339, 481-487 (2002) 16. C. Beaumont and F. Canonne-Hergaux, Iransfus. Clin. (2007) 15. D. Meyrick, 